\title{
Concurrent amplification of Zika, chikungunya, and yellow fever virus in a sylvatic focus of arboviruses in Southeastern Senegal, 2015
}

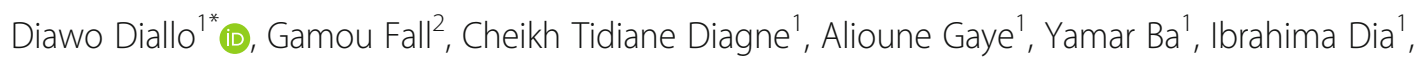
Ousmane Faye ${ }^{2}$ and Mawlouth Diallo ${ }^{1}$

\begin{abstract}
Background: Chikungunya (CHIKV), yellow fever (YFV) and Zika (ZIKV) viruses circulate in sylvatic transmission cycles in southeastern Senegal, where they share common hosts and vectors. All three viruses undergo periodic amplifications, during which they are detected in mosquitoes and sometimes in hosts. However, little is known about their spatio-temporal patterns in years in which they undergo concurrent amplification. The aim of this study was to describe the co-amplification of ZIKV, CHIKV, and YFV, and the daily dynamics of these arboviruses and theirs vectors within villages in southeastern Senegal.

Results: Mosquitoes were collected monthly from July to December 2015. Each evening, from 6 to 9 PM, landing collections were performed by teams of 3 persons working simultaneously in 70 sites situated in forest (canopy and ground), savannah, agriculture, barren, and village (indoor and outdoor) land covers. Collections within villages were continued until 6 AM. Mosquitoes were tested for virus infection by virus isolation and RT-PCR. Seventy-five mosquito pools comprising 10 mosquito species contained at least one virus. Ae. furcifer and Ae. luteocephalus were infected by all three viruses, Ae. taylori by YFV and ZIKV, and remaining seven species by only, only YFV or only ZIKV. No single mosquito pool contained more than one virus. CHIKV was the only virus detected in all land cover classes and was found in the greatest number of sampling sites $(32.9 \%, n=70)$. The proportion of sites in which more than one virus was detected was less than 6\%. Ae. aegypti formosus, Ae. furcifer, Ae. luteocephalus, Ae. minutus, Ae. vittatus, and An. gambiae were found within villages. These vectors were mainly active around dusk but Ae. furcifer was collected until dawn. All viruses save ZIKV were detected indoors and outdoors, mainly around dusk. Virus positive pools were detected over 2, 3 and 4 months for YFV, CHIKV and ZIKV, respectively.
\end{abstract}

Conclusion: Our data indicate that the distribution of different vector species and different arboviruses vary substantially between sites, suggesting that CHIKV, YFV, and ZIKV may have different transmission cycles in Southeastern Senegal.

Keywords: Zika virus, Chikungunya virus, Yellow fever virus, Amplification, Concurrent, Mosquito vectors, Southeastern Senegal

\footnotetext{
* Correspondence: Diawo.DIALLO@pasteur.Sn

'Pôle de Zoologie Médicale, Institut Pasteur de Dakar, 36 Avenue Pasteur, BP 220, Dakar, Senegal

Full list of author information is available at the end of the article
}

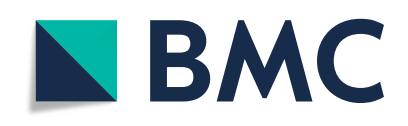

(- The Author(s). 2020 Open Access This article is licensed under a Creative Commons Attribution 4.0 International License, which permits use, sharing, adaptation, distribution and reproduction in any medium or format, as long as you give appropriate credit to the original author(s) and the source, provide a link to the Creative Commons licence, and indicate if changes were made. The images or other third party material in this article are included in the article's Creative Commons licence, unless indicated otherwise in a credit line to the material. If material is not included in the article's Creative Commons licence and your intended use is not permitted by statutory regulation or exceeds the permitted use, you will need to obtain permission directly from the copyright holder. To view a copy of this licence, visit http://creativecommons.org/licenses/by/4.0/. The Creative Commons Public Domain Dedication waiver (http://creativecommons.org/publicdomain/zero/1.0/) applies to the data made available in this article, unless otherwise stated in a credit line to the data. 


\section{Background}

Southeastern Senegal is known as an enzootic focus of several arboviruses of medical and veterinary importance [1]. Indeed since 1972 more than 39 viral species have been isolated from mosquitoes, pheblotomes or rodents during arbovirus surveillance programs in the area [2-4], including yellow fever and Zika (YFV and ZIKV, Flaviviridae: Flavivirus) and chikungunya (CHIKV, genus Alphavirus, family Togaviridae). These three viruses are mainly transmitted between arboreal Aedes vectors and nonhuman primates in this area, where they utilize an overlapping suite of vectors and hosts. However, some studies suggest the possible involvement of additional vertebrate and mosquito species in secondary transmission cycles of these arboviruses [5]. Human are not indispensables hosts in the sylvatic cycle of these arboviruses but may become infected during activities inside forests or directly within villages, where Ae. furcifer and Ae. vittatus have been found infected and feeding readily on humans $[4,6,7]$.

These arboviruses have recently undergone range expansions, producing frequent and devastating outbreaks in Africa, America, Asia and Europe [8-11]. They are transmitted between human by mainly Ae. aegypti and secondarily Ae. albopictus [12-14].

Despite the fact that they share the same epidemiological system, these arboviruses showed some differences in their use of mosquito vectors and vertebrate hosts. Additionally, in southeastern Senegal they undergo different amplification cycles, with a 6 year period for YFV and a 4 year period for ZIKV and CHIKV [15], and have generally been amplified in different years. Indeed, high amplification of CHIKV was detected in 1975, 1979, 1983, 1992, 2009; 1977-78, 1983, 1987, 1993, 2001-2 and 2010, YFV amplification was detected in 1973, 1976, 1979-80, 1984-89, 1993, 1997, and ZIKV amplification was detected in 1988, 1990, and 2011 [2, 16, 17]. Although several studies have investigated the amplification of each virus individually, little is known about the dynamics of concurrent amplification of all three viruses (co-amplification). Thus, the aims of this paper are to describe 1) the spatio-temporal dynamics of co-amplification of ZIKV, CHIKV, and YFV in southeastern Senegal in 2015, and 2) the daily dynamics of mosquito vectors and the arboviruses they carry within villages during this coamplification.

\section{Results}

For the evening sampling in the 70 sites, 10,785 mosquitoes belonging to 7 genera and 48 species were collected and grouped in 1623 pools for viral testing (Table 1). Ten mosquito species were found to be infected by at least one of the three target arboviruses. Among these, Ae. furcifer $(n=2823)$, Ae. dalzieli $(n=2286)$, Ae. vittatus $(n=2034)$, and Ae. luteocephalus $(n=1107)$ made $76.5 \%$ of the total mosquitoes collected (i.e. both infected and uninfected specimens). The other species found to be positive for at least one virus included Ae. aegypti formosus (2.2\% of the total mosquito collection), Ae. minutus (1.8\%), An. gambiae (1.7\%), Ma. uniformis (1.7\%), Ae. taylori (1.2\%), and Ae. africanus (1\%). Among species comprising more than $1 \%$ of the total, only An. coustani (3.9\%) and Ae. argenteopunctatus (2.4\%) were not found to carry any of the three target viruses.

Seventy-five pools were found positive for one of the viruses: ZIKV (23 pools), YFV (20) and or CHIKV (32) (Table 1). Only Ae. furcifer (18 pools positive for CHIKV, 8 pools positive for YFV; 9 pools positive for ZIKV) and Ae. luteocephalus (4 pools positive for CHIKV, 7 pools positive for YFV, 11 pools positive for ZIKV) were associated with all three viruses. Ae. taylori was positive for YFV and ZIKV (1 pool each) while all the other species were positive for only one of the three viruses: CHIKV (Ae. aegypti formosus $=2$ pools, Ae. minutus $=1$ pool, and An. gambiae $=3$ pools), YFV (Ae. vittatus and Ae. africanus; 4 pools for each species) or ZIKV (Ae. dalzieli and Ma. uniformis; 1 pool for each species). No mosquito pool was co-infected with more than one virus. The spatio-temporal amplification patterns of viruses varied according to viral species and the vector involved (Fig. 1, Table 2).

For CHIKV, the mean MFIR per thousand pooled mosquitoes (Table 1) that varied between $3.6 \%$ for $A e$. luteocephalus and $16.4 \%$ for An. gambiae were comparable (Fisher's Exact Test: $p=0.2$ ). The infection rates of the vectors varied significantly for YFV (Fisher's Exact Test: $p=0.0006$ ) and ZIKV (Fisher's Exact Test: $p=0.0003)$. Differences in MFIR of vectors were due to the higher infection rates of Ae. africanus and Ae. taylori for YFV and the lower infection rate of Ae. dalzieli for ZIKV. The mean entomogical inoculation rates (Table $1)$, indicate that the main vectors were Ae. furcifer (64.5\% of the transmission), Ae. luteocephalus (14.3\%), An. gambiae (10.7\%) and Ae. aegypti formosus (7.1\%) for CHIKV, Ae. furcifer (33.3\%), Ae. luteocephalus (29.2\%), Ae. africanus and Ae. vittatus (16.7\% each) for YFV, Ae. luteocephalus (47.8\%) and Ae. furcifer (39.1\%) for ZIKV.

As shown in Fig. 1 and Table 2, CHIKV was detected in all land cover classes, while YFV was not detected in agriculture or barren land and ZIKV was not detected in agriculture or outdoors in villages. Moreover, CHIKV, which was was found in $32.9 \%$ of the 70 sampling sites, was detected significantly more often than the other two viruses $\left(x^{2}=18.5, d f=2, p<0.001\right)$. ZIKV was detected in $20 \%$ of sites and YFV in $18.6 \%$ of sites, with statistically comparable detection frequencies $\left(x^{2}=0, d f=1\right.$, $p=1$ ). While $55.7 \%$ of the sampling sites were found positive for at least one virus, the proportion of sites with co-occurrence of 2 or 3 viruses were low and 
Table 1 Mosquitoes collected, arboviruses isolated,minimum field infection and entomological inoculation rates of vectors in southeastern Senegal, 2015

\begin{tabular}{|c|c|c|c|c|c|c|c|c|c|c|c|c|c|c|c|}
\hline \multirow[t]{2}{*}{ Species } & \multicolumn{4}{|c|}{ Mosquitoes } & \multicolumn{4}{|c|}{ Viral strains } & \multicolumn{3}{|c|}{ MFIR\%o } & \multirow[t]{2}{*}{$\mathrm{BR}(\mathrm{F} / \mathrm{P} / \mathrm{E})$} & \multicolumn{3}{|l|}{ EIR } \\
\hline & Females & Males & Total & $\%$ & $\mathrm{CHIKV}$ & YFV & $\mathrm{ZIKV}$ & Total & $\mathrm{CHIKV}$ & YFV & $\mathrm{ZIKV}$ & & $\mathrm{CHIKV}$ & YFV & $\mathrm{ZIKV}$ \\
\hline Aedes aegypti formosus & 233 & 3 & 236 & 2.2 & 2 & 0 & 0 & 2 & 8.6 & 0.0 & 0.0 & 0.2 & 0.3 & 0.0 & 0.0 \\
\hline Ae. africanus & 106 & 0 & 106 & 1.0 & 0 & 4 & 0 & 4 & 0.0 & 37.7 & 0.0 & 0.1 & 0.0 & 0.6 & 0.0 \\
\hline Ae. argenteopunctatus & 264 & 0 & 264 & 2.4 & 0 & 0 & 0 & 0 & 0.0 & 0.0 & 0.0 & 0.2 & 0.0 & 0.0 & 0.0 \\
\hline Ae. centropunctatus & 86 & 0 & 86 & 0.8 & 0 & 0 & 0 & 0 & 0.0 & 0.0 & 0.0 & 0.1 & 0.0 & 0.0 & 0.0 \\
\hline Ae. cumminsii & 3 & 0 & 3 & 0.0 & 0 & 0 & 0 & 0 & 0.0 & 0.0 & 0.0 & 0.0 & 0.0 & 0.0 & 0.0 \\
\hline Ae. dalzieli & 2286 & 0 & 2286 & 21.2 & 0 & 0 & 1 & 1 & 0.0 & 0.0 & 0.4 & 1.8 & 0.0 & 0.0 & 0.1 \\
\hline Ae. fowleri & 20 & 0 & 20 & 0.2 & 0 & 0 & 0 & 0 & 0.0 & 0.0 & 0.0 & 0.0 & 0.0 & 0.0 & 0.0 \\
\hline Ae. furcifer & 2763 & 60 & 2823 & 26.2 & 18 & 8 & 9 & 35 & 6.5 & 2.9 & 3.3 & 2.2 & 2.6 & 1.2 & 1.3 \\
\hline Ae. hirsutus & 45 & 0 & 45 & 0.4 & 0 & 0 & 0 & 0 & 0.0 & 0.0 & 0.0 & 0.0 & 0.0 & 0.0 & 0.0 \\
\hline Ae. luteocephalus & 1106 & 1 & 1107 & 10.3 & 4 & 7 & 11 & 22 & 3.6 & 6.3 & 9.9 & 0.9 & 0.6 & 1.0 & 1.6 \\
\hline Ae. mcintoshi & 5 & 0 & 5 & 0.0 & 0 & 0 & 0 & 0 & 0.0 & 0.0 & 0.0 & 0.0 & 0.0 & 0.0 & 0.0 \\
\hline Ae. metallicus & 54 & 0 & 54 & 0.5 & 0 & 0 & 0 & 0 & 0.0 & 0.0 & 0.0 & 0.0 & 0.0 & 0.0 & 0.0 \\
\hline Ae. minutus & 198 & 0 & 198 & 1.8 & 1 & 0 & 0 & 1 & 5.1 & 0.0 & 0.0 & 0.2 & 0.1 & 0.0 & 0.0 \\
\hline Ae. neoafricanus & 2 & 0 & 2 & 0.0 & 0 & 0 & 0 & 0 & 0.0 & 0.0 & 0.0 & 0.0 & 0.0 & 0.0 & 0.0 \\
\hline Ae. ochraceus & 4 & 0 & 4 & 0.0 & 0 & 0 & 0 & 0 & 0.0 & 0.0 & 0.0 & 0.0 & 0.0 & 0.0 & 0.0 \\
\hline Ae. sudanensis & 2 & 0 & 2 & 0.0 & 0 & 0 & 0 & 0 & 0.0 & 0.0 & 0.0 & 0.0 & 0.0 & 0.0 & 0.0 \\
\hline Ae. taylori & 123 & 7 & 130 & 1.2 & 0 & 1 & 1 & 2 & 0.0 & 8.1 & 8.1 & 0.1 & 0.0 & 0.1 & 0.1 \\
\hline Ae. unilineatus & 49 & 0 & 49 & 0.5 & 0 & 0 & 0 & 0 & 0.0 & 0.0 & 0.0 & 0.0 & 0.0 & 0.0 & 0.0 \\
\hline Ae. vittatus & 2006 & 28 & 2034 & 18.9 & 0 & 4 & 0 & 4 & 0.0 & 2.0 & 0.0 & 1.6 & 0.0 & 0.6 & 0.0 \\
\hline Anopheles coustani & 422 & 0 & 422 & 3.9 & 0 & 0 & 0 & 0 & 0.0 & 0.0 & 0.0 & 0.3 & 0.0 & 0.0 & 0.0 \\
\hline An. domicola & 3 & 0 & 3 & 0.0 & 0 & 0 & 0 & 0 & 0.0 & 0.0 & 0.0 & 0.0 & 0.0 & 0.0 & 0.0 \\
\hline An. flavicosta & 36 & 0 & 36 & 0.3 & 0 & 0 & 0 & 0 & 0.0 & 0.0 & 0.0 & 0.0 & 0.0 & 0.0 & 0.0 \\
\hline An. freetownensis & 6 & 0 & 6 & 0.1 & 0 & 0 & 0 & 0 & 0.0 & 0.0 & 0.0 & 0.0 & 0.0 & 0.0 & 0.0 \\
\hline An. funestus & 74 & 0 & 74 & 0.7 & 0 & 0 & 0 & 0 & 0.0 & 0.0 & 0.0 & 0.1 & 0.0 & 0.0 & 0.0 \\
\hline An. gambiae & 183 & 0 & 183 & 1.7 & 3 & 0 & 0 & 3 & 16.4 & 0.0 & 0.0 & 0.1 & 0.4 & 0.0 & 0.0 \\
\hline An. hancocki & 8 & 0 & 8 & 0.1 & 0 & 0 & 0 & 0 & 0.0 & 0.0 & 0.0 & 0.0 & 0.0 & 0.0 & 0.0 \\
\hline An. maculipalpis & 1 & 0 & 1 & 0.0 & 0 & 0 & 0 & 0 & 0.0 & 0.0 & 0.0 & 0.0 & 0.0 & 0.0 & 0.0 \\
\hline An. nili & 9 & 0 & 9 & 0.1 & 0 & 0 & 0 & 0 & 0.0 & 0.0 & 0.0 & 0.0 & 0.0 & 0.0 & 0.0 \\
\hline An. pharoensis & 11 & 0 & 11 & 0.1 & 0 & 0 & 0 & 0 & 0.0 & 0.0 & 0.0 & 0.0 & 0.0 & 0.0 & 0.0 \\
\hline An. rufipes & 19 & 1 & 20 & 0.2 & 0 & 0 & 0 & 0 & 0.0 & 0.0 & 0.0 & 0.0 & 0.0 & 0.0 & 0.0 \\
\hline An. ziemanni & 40 & 1 & 41 & 0.4 & 0 & 0 & 0 & 0 & 0.0 & 0.0 & 0.0 & 0.0 & 0.0 & 0.0 & 0.0 \\
\hline Culex annulioris & 10 & 0 & 10 & 0.1 & 0 & 0 & 0 & 0 & 0.0 & 0.0 & 0.0 & 0.0 & 0.0 & 0.0 & 0.0 \\
\hline Cx. antennatus & 15 & 4 & 19 & 0.2 & 0 & 0 & 0 & 0 & 0.0 & 0.0 & 0.0 & 0.0 & 0.0 & 0.0 & 0.0 \\
\hline Cx. bitaeniorhynchus & 45 & 0 & 45 & 0.4 & 0 & 0 & 0 & 0 & 0.0 & 0.0 & 0.0 & 0.0 & 0.0 & 0.0 & 0.0 \\
\hline Cx. cinereus & 31 & 9 & 40 & 0.4 & 0 & 0 & 0 & 0 & 0.0 & 0.0 & 0.0 & 0.0 & 0.0 & 0.0 & 0.0 \\
\hline Cx. decens & 5 & 0 & 5 & 0.0 & 0 & 0 & 0 & 0 & 0.0 & 0.0 & 0.0 & 0.0 & 0.0 & 0.0 & 0.0 \\
\hline Cx. ethiopicus & 2 & 0 & 2 & 0.0 & 0 & 0 & 0 & 0 & 0.0 & 0.0 & 0.0 & 0.0 & 0.0 & 0.0 & 0.0 \\
\hline Cx. neavei & 13 & 0 & 13 & 0.1 & 0 & 0 & 0 & 0 & 0.0 & 0.0 & 0.0 & 0.0 & 0.0 & 0.0 & 0.0 \\
\hline Cx. nebulosus & 1 & 0 & 1 & 0.0 & 0 & 0 & 0 & 0 & 0.0 & 0.0 & 0.0 & 0.0 & 0.0 & 0.0 & 0.0 \\
\hline Cx. perfuscus & 17 & 0 & 17 & 0.2 & 0 & 0 & 0 & 0 & 0.0 & 0.0 & 0.0 & 0.0 & 0.0 & 0.0 & 0.0 \\
\hline Cx. poicilipes & 30 & 0 & 30 & 0.3 & 0 & 0 & 0 & 0 & 0.0 & 0.0 & 0.0 & 0.0 & 0.0 & 0.0 & 0.0 \\
\hline Cx. quinquefasciatus & 92 & 6 & 98 & 0.9 & 0 & 0 & 0 & 0 & 0.0 & 0.0 & 0.0 & 0.1 & 0.0 & 0.0 & 0.0 \\
\hline
\end{tabular}


Table 1 Mosquitoes collected, arboviruses isolated,minimum field infection and entomological inoculation rates of vectors in southeastern Senegal, 2015 (Continued)

\begin{tabular}{|c|c|c|c|c|c|c|c|c|c|c|c|c|c|c|c|}
\hline \multirow[t]{2}{*}{ Species } & \multicolumn{4}{|c|}{ Mosquitoes } & \multicolumn{4}{|c|}{ Viral strains } & \multicolumn{3}{|c|}{ MFIR\%o } & \multirow[t]{2}{*}{$\mathrm{BR}(\mathrm{F} / \mathrm{P} / \mathrm{E})$} & \multicolumn{3}{|l|}{$E I R$} \\
\hline & Females & Males & Total & $\%$ & $\mathrm{CHIKV}$ & YFV & ZIKV & Total & $\mathrm{CHIKV}$ & YFV & $\mathrm{ZIKV}$ & & CHIKV & YFV & $\mathrm{ZIKV}$ \\
\hline Cx. tigripes & 1 & 0 & 1 & 0.0 & 0 & 0 & 0 & 0 & 0.0 & 0.0 & 0.0 & 0.0 & 0.0 & 0.0 & 0.0 \\
\hline Eretmapodites chrysogaster & 3 & 0 & 3 & 0.0 & 0 & 0 & 0 & 0 & 0.0 & 0.0 & 0.0 & 0.0 & 0.0 & 0.0 & 0.0 \\
\hline Er. quinquevittatus & 1 & 0 & 1 & 0.0 & 0 & 0 & 0 & 0 & 0.0 & 0.0 & 0.0 & 0.0 & 0.0 & 0.0 & 0.0 \\
\hline Mansonia africana & 48 & 0 & 48 & 0.4 & 0 & 0 & 0 & 0 & 0.0 & 0.0 & 0.0 & 0.0 & 0.0 & 0.0 & 0.0 \\
\hline Ma. uniformis & 182 & 0 & 182 & 1.7 & 0 & 0 & 1 & 1 & 0.0 & 0.0 & 5.5 & 0.1 & 0.0 & 0.0 & 0.1 \\
\hline Uranotaenia balfouri & 2 & 0 & 2 & 0.0 & 0 & 0 & 0 & 0 & 0.0 & 0.0 & 0.0 & 0.0 & 0.0 & 0.0 & 0.0 \\
\hline Total & 10,665 & 120 & 10,785 & 100.0 & & & & & & & & & & & \\
\hline
\end{tabular}

\% percentage of the total mosquito collected, CHIKV chikungunya virus, YFV yellow fever virus, ZIKV Zika virus, MFIR\%o Minimum field infection rate per thousand mosquitoes tested, $B R$ Biting rate, F/P/E females per person per evening, EIR Entomological inoculation rates (number of infected mosquito bites per person between July and December); Ae., Aedes; An., Anopheles; Cx., Culex; Er., Eretmapodites; Ma., Mansonia

comparable (Fisher's Exact Test: $p=0.8$ ), ranging from about 1 to $5 \%$.

MFIR of each vector species for CHIKV, YFV, and ZIKV (Table 3) were not significantly different between landcover classes investigated (Fisher's Exact Test: $p>0.06$ ), except Ae. luteocephalus for ZIKV (Fisher's Exact Test: $p=0.03$ ). The infection rate of the Ae. luteocephalus population collected in villages indoor was significantly higher compared to the other populations. Species involved and their relative importance in the transmission varied by virus and landcover class (Table 3 ).

Several vectors including Ae. aegypti formosus, Ae. furcifer, Ae. luteocephalus, Ae. minutus, Ae. vittatus, and An. gambiae were found both indoors and outdoors within villages. These vectors were mainly active around dusk between $19 \mathrm{~h}$ and $21 \mathrm{~h}$ but Ae. furcifer was collected in lesser abundance until dawn (Table 4). Both CHIKV and YFV were detected in mosquitoes collected indoors and outdoors, while ZIKV was detected only indoors, mainly around dusk. Only YFV was detected in
Ae. furcifer collected indoors and outdoors between $21 \mathrm{~h}$ and midnight.

Seasonally, positive mosquito pools were collected from July to September for CHIKV, October to November for YFV, and August to November for ZIKV (Table 5). The entomogical inoculation rates, indicate that Ae. vittatus and Ae. luteocephalus were the main vectors of CHIKV in July. This role was played by Ae. furcifer the following 2 months. For YFV, Ae. luteocephalus and Ae. furcifer were the main vectors at the beginning of the transmission in October while Ae. furcifer played a main role in November. Ae. luteocephalus and Ae. furcifer had equal importance in ZIKV transmission between August and October and were supplanted by Ae. dalzieli and Ae. taylori in November.

\section{Discussion}

In this study we describe a co-amplification of ZIKV, YFV, and CHIKV in southeastern Senegal of unprecedented scope. Amplifications of CHIKV [7], YFV [4] and

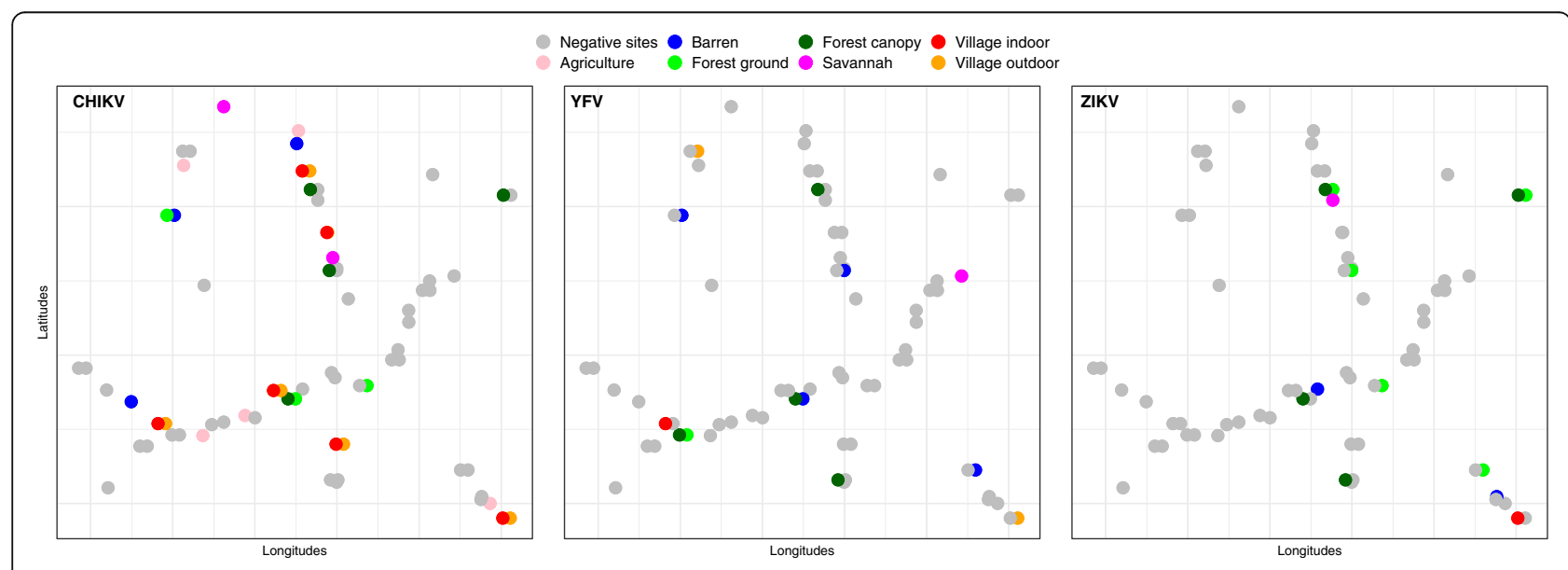

Fig. 1 Sampling sites with Zika, chikungunya, and yellow fever viruses positive mosquito pools in southeastern Senegal, 2015 
Table 2 Land cover distribution of arboviruses detected from mosquitoes collected in southeastern Senegal, 2015

\begin{tabular}{|c|c|c|c|c|}
\hline Viruses & Land cover class & No. +sites & No. + pools & Species (No. + pools; No. + sites) \\
\hline \multirow[t]{10}{*}{$\mathrm{CHIKV}$} & Forest canopy & 3 & 7 & Ae. aegypti formosus $(1 ; 1)$, Ae. furcifer $(3 ; 1)$, Ae. luteocephalus $(3 ; 2)$ \\
\hline & Forest ground & 3 & 3 & Ae. furcifer $(2 ; 2)$, Ae. luteocephalus $(1 ; 1)$ \\
\hline & Agriculture & 5 & 5 & Ae. furcifer $(4 ; 4)$, Ae. vittatus $(1 ; 1)$ \\
\hline & Barren & 2 & 4 & Ae. furcifer (2;2), Ae. vittatus $(2 ; 1)$ \\
\hline & Savannah & 2 & 1 & Ae. furcifer $(2 ; 2)$ \\
\hline & Village indoor & 2 & 4 & Ae. aegypti formosus $(1 ; 1)$, Ae. furcifer $(1 ; 1)$, Ae. minutus $(1 ; 1)$, Ae. vittatus $(1 ; 1)$ \\
\hline & Village outdoor & 6 & 7 & Ae. furcifer $(4 ; 4)$, An. gambiae $(3 ; 3)$ \\
\hline & Forest canopy & 4 & 7 & Ae. africanus $(2 ; 1)$, Ae. furcifer $(1 ; 1)$, Ae. luteocephalus $(3 ; 2)$, Ae. taylori $(1 ; 1)$ \\
\hline & Forest ground & 5 & 9 & Ae. africanus (2;2), Ae. furcifer (3;3), Ae. luteocephalus (4;3) \\
\hline & Agriculture & 0 & 0 & \\
\hline \multirow[t]{6}{*}{ YFV } & Barren & 0 & 0 & \\
\hline & Savannah & 1 & 1 & Ae. furcifer $(1 ; 1)$ \\
\hline & Village indoor & 1 & 1 & Ae. furcifer $(1 ; 1)$ \\
\hline & Village outdoor & 2 & 2 & Ae. furcifer $(2 ; 2)$ \\
\hline & Forest canopy & 5 & 9 & Ae. furcifer (3;3), Ae. luteocephalus (5;4), Ae. dalzieli $(1 ; 1)$ \\
\hline & Forest ground & 5 & 8 & Ae. furcifer $(3 ; 3)$, Ae. luteocephalus $(3 ; 3)$, Ae. taylori $(1 ; 1)$, Ma. uniformis $(1 ; 1)$ \\
\hline \multirow[t]{5}{*}{ ZIKV } & Agriculture & 0 & 0 & \\
\hline & Barren & 2 & 3 & Ae. furcifer $(2 ; 2)$, Ae. luteocephalus $(1 ; 1)$ \\
\hline & Savannah & 1 & 1 & Ae. luteocephalus $(1 ; 1)$ \\
\hline & Village indoor & 1 & 2 & Ae. furcifer $(1 ; 1)$, Ae. luteocephalus $(1 ; 1)$ \\
\hline & Village outdoor & 0 & 0 & \\
\hline
\end{tabular}

No. + sites Number of positives sites, No. + pools Number of pools found positive, CHIKV chikungunya virus, YFV yellow fever virus, ZIKV Zika virus; Ae., Aedes; An., Anopheles; Ma., Mansonia

ZIKV [17] were most recently detected in this system in 2009, 2010 and 2011, respectively. These three viruses were last isolated concurrently in 1990 during an outbreak of dengue virus is southeastern Senegal [18]. The low number of strains of these 3 viruses detected in 1990 (3 ZIKV strains, 2 YFV strains and 1 CHIKV strain) may be due to a low-level of circulation of these arboviruses in the sylvatic area or the low number of sites (6 sampling sites) and land cover classes investigated. Interestingly, in the same year (2015) that it was detected in our surveillance system, ZIKV was responsible for huge outbreaks in Brazil [19] and several countries of Latin America [20], and Cabo Verde [21] with the first association of this virus with severe maternal, neonatal and child health complications.

The lack of co-infection of individual mosquito pools with multiple arboviruses could be linked to the low percentage of sites where co-amplification occurred. Experimental work has shown that a single mosquito specimen can be coinfected and effectively transmit two or three arboviruses [22-25]. The low level of co-amplification strongly suggests that these arboviruses have different spatial amplification patterns and probably also different amplification cycles despite the fact that they share the same main vectors (Ae. furcifer and Ae. luteocephalus) in this and previous studies $[4,6,7]$. The other facts suggesting different amplification cycles of CHIKV, YFV, and ZIKV, includes differences in the role of the main vectors in the landcover classes investigated, number of species involved as vectors (6 CHIKV, 4 YFV, 5 ZIKV), and temporal dynamics of the virus (3 months for CHIKV, 2 for YFV and 4 for ZIKV). The same pattern (with more vectors involved and more months when the infection were detected) was observed in previous studies in the same area when these viruses were detected in 3 different seasons [4, 6, 7]. While not investigated in this study, non-human primates (NHP) are considered as the main vertebrate hosts involved in the sylvatic cycle of CHIKV, YFV, and ZIKV. These NHPs, including Chlorocebus sabaeus, Erythrocebus patas and Papio papio, were found infected by virus isolation and serology in the study area $[12,17]$. The role played by these NHPs on the maintenance of these viruses over time was questioned. Thus, investigations on the potential role of other vertebrate hosts detected Avian blood meals from Ae. furcifer and Ae. taylori [5]. The results also suggested a possible involvement of several wild vertebrates, including birds, rodents, and bats in other transmission cycles of these viruses [17, 26-28]. Thus, these differences in amplification patterns may reflect 
Table 3 Minimum field infection and entomological inoculation rates of arbovirus vectors in southeastern Senegal, 2015

\begin{tabular}{|c|c|c|}
\hline Virus & Land cover class & Species (MFIR \%; EIR) \\
\hline \multirow[t]{10}{*}{$\mathrm{CHIKV}$} & Forest canopy & Ae. aegypti formosus (55.6; 1.02), Ae. furcifer (4.06; 3.05), Ae. luteocephalus $(4.92 ; 3.05)$ \\
\hline & Forest ground & Ae. furcifer (6.27; 2.03), Ae. luteocephalus (2.6; 1.02) \\
\hline & Agriculture & Ae. furcifer (13.38; 4.07), Ae. vittatus (1.89; 1.02) \\
\hline & Barren & Ae. furcifer $(4.57 ; 2.04)$, Ae. vittatus $(3.16 ; 2.03)$ \\
\hline & Savannah & Ae. furcifer $(5.76 ; 2.03)$ \\
\hline & Village indoor & Ae. aegypti formosus (50; 1.02), Ae. furcifer (5.92; 1.02), Ae. minutus (166.67; 1.02), Ae. vittatus (52.63; 1.02) \\
\hline & Village outdoor & Ae. furcifer (8.83; 4.07), An. gambiae $(44.11 ; 3.05)$ \\
\hline & Forest canopy & Ae. africanus (40; 2.03), Ae. furcifer (1.35; 1.01), Ae. luteocephalus (4.92; 3.05), Ae. taylori (11.9; 1.02) \\
\hline & Forest ground & Ae. africanus (36.36;2.03), Ae. furcifer (9.4; 3.05), Ae. luteocephalus (10.42; 4.07) \\
\hline & Agriculture & \\
\hline \multirow[t]{6}{*}{ YFV } & Barren & \\
\hline & Savannah & Ae. furcifer $(2.88 ; 1.02)$ \\
\hline & Village indoor & Ae. furcifer $(5.92 ; 1.02)$ \\
\hline & Village outdoor & Ae. furcifer $(4.41 ; 2.03)$ \\
\hline & Forest canopy & Ae. furcifer (4.06; 3.05), Ae. luteocephalus (8.2; 5.09), Ae. dalzieli (3.28; 1.02) \\
\hline & Forest ground & Ae. furcifer (9.4; 3.05), Ae. luteocephalus (7.81; 3.05), Ae. taylori (47.62; 1.02), Ma. uniformis (66.67; 1.02) \\
\hline \multirow[t]{5}{*}{ ZIKV } & Agriculture & \\
\hline & Barren & Ae. furcifer $(4.57 ; 2.04)$, Ae. luteocephalus $(25.64 ; 1.02)$ \\
\hline & Savannah & Ae. luteocephalus $(21.74 ; 1.02)$ \\
\hline & Village indoor & Ae. furcifer (5.92; 1.02), Ae. luteocephalus (250; 1.02) \\
\hline & Village outdoor & \\
\hline
\end{tabular}

MFIR\%o Minimum field infection rate per thousand mosquitoes tested, EIR Entomological inoculation rates (number of infected mosquito bites per person between July and December)

differences in the community of amplification and reservoir hosts utilized by these viruses.

The host-seeking activities of vectors and transmission of CHIKV, YFV and ZIKV within villages including inside homes, suggest that risk of transmission of sylvatic arboviruses to humans is higher than expected in this population. The involvement of six vector species (Ae. aegypti formosus, Ae. furcifer, Ae. minutus, Ae. luteocephalus, Ae. vittatus and An. gambiae) in arbovirus transmission within villages, including four species (Ae. aegypti formosus, Ae. minutus, Ae. luteocephalus, and An. gambiae) detected for the first time in this study, also highlights the high and growing risk of human exposure to arbovirus in domestic environment in southeastern Senegal. It also suggests that all mosquito species present in this domestic environment should be considered potential arbovirus vectors, and their vector competence should be evaluated. The continuous activities of these vectors from dusk to dawn and the transmission of YFV until midnight, after people went to bed, suggest that malaria control interventions including indoor spatial dispersion of insecticides and insecticide-treated nets may be helpful in controlling YFV transmission.

Aedes furcifer and Ae. luteocephalus pools were tested positive for CHIKV, YFV and ZIKV suggesting a broad susceptibility of these species to arboviruses. Indeed, because they were the most frequently associated to these viruses and among the most abundant species in the sylvatic environment, these species were previously incriminated as the main vectors during sylvatic outbreaks of CHIKV, YFV and ZIKV in southeastern Senegal $[2,4,6]$ and several west African countries [17, 29]. However, despite the fact that these two vectors breed mainly in tree-holes [30], the spatial distribution of these vectors suggests that Ae. furcifer (found infected in all land cover classes investigated) play an important role both as an epizootic vector (among monkeys in the forest canopies) and a bridge vector (transmitting the viruses to human within villages), whereas Ae. luteocephalus played an important role probably only as an epizootic vector [6, 7].

As in the consecutive amplifications of CHIKV, YFV and ZIKV between 2009 and 2011 [4, 6, 7], ZIKV had the longest temporal period of transmission, followed by CHIKV and YFV. For each of these viruses, the duration of transmission was a month shorter compared to the amplifications observed between 2009 and 2011. It is also important to indicate that fewer mosquito species and fewer sampling sites were found infected during this co-amplification compared to the amplifications between 2009 and 2011, with the same sites sampled, suggesting 
Table 4 Mosquitoes collected and arboviruses isolated within villages indoors and outdoors in southeastern Senegal, 2015

\begin{tabular}{|c|c|c|c|c|c|c|c|c|c|c|c|c|c|}
\hline & \multirow[t]{2}{*}{ Hours } & \multicolumn{2}{|c|}{$\begin{array}{l}\text { Ae. aegypti } \\
\text { formosus }\end{array}$} & \multicolumn{2}{|l|}{ Ae. furcifer } & \multicolumn{2}{|c|}{ An. gambiae } & \multicolumn{2}{|c|}{ Ae. luteocephalus } & \multicolumn{2}{|c|}{ Ae. minutus } & \multicolumn{2}{|c|}{ Ae. vittatus } \\
\hline & & Outdoor & Indoor & Outdoor & Indoor & Outdoor & Indoor & Outdoor & Indoor & Outdoor & Indoor & Outdoor & Indoor \\
\hline \multirow{11}{*}{$\begin{array}{l}\text { Number of } \\
\text { Mosquito } \\
\text { collected }\end{array}$} & $19 \mathrm{~h}-21 \mathrm{~h}$ & 96 & 20 & 423 & 199 & 68 & 24 & 5 & 4 & 12 & 6 & 116 & 19 \\
\hline & $21 \mathrm{~h}-22 \mathrm{~h}$ & & & 33 & 8 & & & & & & & & \\
\hline & $22 \mathrm{~h}-23 \mathrm{~h}$ & & & 18 & 3 & & & & & & & 1 & \\
\hline & $23 \mathrm{~h}-00 \mathrm{~h}$ & & & 17 & 6 & & & & & & & & \\
\hline & $00 \mathrm{~h}-01 \mathrm{~h}$ & & & 4 & 4 & & & & & & & & \\
\hline & $01 \mathrm{~h}-02 \mathrm{~h}$ & & & 7 & 4 & & & & & & & & \\
\hline & $02 \mathrm{~h}-03 \mathrm{~h}$ & & & 8 & 1 & & & & 1 & & & & \\
\hline & $03 \mathrm{~h}-04 \mathrm{~h}$ & & & 5 & 2 & & & & & & & & \\
\hline & $04 \mathrm{~h}-05 \mathrm{~h}$ & & & 3 & & & & & & & & & \\
\hline & $05 \mathrm{~h}-06 \mathrm{~h}$ & & & 1 & 1 & & & & & & & & \\
\hline & Total & 96 & 20 & 519 & 228 & 68 & 24 & 5 & 5 & 12 & 6 & 117 & 19 \\
\hline \multirow{11}{*}{$\begin{array}{l}\text { Number of } \\
\text { viral strains } \\
\text { isolated }\end{array}$} & $19 \mathrm{~h}-21 \mathrm{~h}$ & & $1 \mathrm{CHIKV}$ & $4 \mathrm{CHIKV}, 2 \mathrm{YFV}$ & $1 \mathrm{CHIKV}, 1 \mathrm{YFV}, 1 \mathrm{ZIKV}$ & $3 \mathrm{CHIKV}$ & & & $1 \mathrm{ZIKV}$ & & $1 \mathrm{CHIKV}$ & & $1 \mathrm{CHIKV}$ \\
\hline & $21 \mathrm{~h}-22 \mathrm{~h}$ & & & & 2 YFV & & & & & & & & \\
\hline & $22 \mathrm{~h}-23 \mathrm{~h}$ & & & & 1 YFV & & & & & & & & \\
\hline & $23 \mathrm{~h}-00 \mathrm{~h}$ & & & 1 YFV & & & & & & & & & \\
\hline & $00 \mathrm{~h}-01 \mathrm{~h}$ & & & & & & & & & & & & \\
\hline & $01 \mathrm{~h}-02 \mathrm{~h}$ & & & & & & & & & & & & \\
\hline & $02 \mathrm{~h}-03 \mathrm{~h}$ & & & & & & & & & & & & \\
\hline & $03 \mathrm{~h}-04 \mathrm{~h}$ & & & & & & & & & & & & \\
\hline & $04 \mathrm{~h}-05 \mathrm{~h}$ & & & & & & & & & & & & \\
\hline & $05 \mathrm{~h}-06 \mathrm{~h}$ & & & & & & & & & & & & \\
\hline & Total & & 1 & 7 & 6 & 3 & & & 1 & & 1 & & 1 \\
\hline
\end{tabular}

CHIKV chikungunya virus, YFV yellow fever virus, ZIKV Zika virus; Ae., Aedes; An., Anopheles

that this co-amplification had a negative impact on the normal dynamics of each of the virus individually.

Our data indicate that mosquito vector activity and arbovirus transmission are highly variable between sites, even those in the same land cover. Mosquito population distribution has been shown to be affected by abundance of their vertebrate blood meal sources [31], thus we speculate that the variation in abundance of particular species may reflect variation in abundance of key host species.

\section{Conclusion}

Our study described the co-amplification of three major arboviruses (ZIKV, CHIKV, and YFV), and the daily dynamics of these arboviruses and theirs vectors within villages in southeastern Senegal. Our results highlighted important spatio-temporal variations in the distribution of the different vectors and arboviruses investigated. Important differences were also observed in the role played by the different vectors in the amplification of the different viruses. These data improve our understanding of the natural histories of arboviruses in the sylvatic environment, and suggest that CHIKV, YFV, and ZIKV may have different transmission cycles in Southeastern Senegal.

\section{Methods}

Study area

Our investigation was done in an area of $1650 \mathrm{~km}^{2}(30$ $\mathrm{km}$ in N-S direction; $55 \mathrm{~km}$ in E-W direction) around Kedougou city $\left(12^{\circ} 33 \mathrm{~N}, 12^{\circ} 11 \mathrm{~W}\right)$ in southeastern Senegal (Fig. 2). This study area was extensively described in previous studies $[6,7,32]$. It is located in the fringes of the Fouta Djallon hills, in the borders of Guinea and Mali. The annual rainfall is about $1200 \mathrm{~mm}$ and the average temperature is $28^{\circ} \mathrm{C}$. Around $84 \%$ of the approximately 156,352 inhabitants of the Kedougou region live in rural areas in small, dispersed villages, and are mainly engaged in agriculture, cattle farming, hunting, and gold mining. Kedougou city is the only large town in the area. The main land cover classes found in the area include forests, savannas, waters, barren lands, agriculture, and villages. The forest land cover is increasingly threatened by human activities including agriculture, charcoal production, gold mining and housing.

\section{Mosquito sampling}

Mosquitoes were collected from July to December 2015 in 70 sites located within the study area. Sites were located in the five main land cover classes of the area 
Table 5 Temporal dynamics of mosquito vectors and arboviruses in southeastern Senegal, 2015

\begin{tabular}{|c|c|c|c|c|c|c|c|c|}
\hline \multirow{2}{*}{\multicolumn{2}{|c|}{ Total mosquitoes collected }} & \multirow{2}{*}{$\begin{array}{l}\text { Species } \\
\text { Ae. aegypti formosus }\end{array}$} & \multirow{2}{*}{$\frac{\text { July }}{132}$} & \multirow{2}{*}{$\begin{array}{l}\text { August } \\
54\end{array}$} & \multirow{2}{*}{$\begin{array}{l}\text { September } \\
18\end{array}$} & \multirow{2}{*}{$\begin{array}{l}\text { October } \\
13\end{array}$} & \multirow{2}{*}{$\frac{\text { November }}{16}$} & \multirow{2}{*}{$\frac{\text { December }}{0}$} \\
\hline & & & & & & & & \\
\hline & & Ae. africanus & 0 & 0 & 0 & 80 & 24 & 2 \\
\hline & & Ae. dalzieli & 18 & 4 & 26 & 1120 & 1106 & 12 \\
\hline & & Ae. furcifer & 1436 & 230 & 339 & 533 & 219 & 6 \\
\hline & & An. gambiae & 8 & 63 & 78 & 10 & 23 & 1 \\
\hline & & Ae. luteocephalus & 608 & 88 & 180 & 179 & 48 & 3 \\
\hline & & Ae. minutus & 117 & 6 & 75 & 0 & 0 & 0 \\
\hline & & Ae. taylori & 47 & 6 & 26 & 26 & 17 & 1 \\
\hline & & Ma. uniformis & 2 & 1 & & 39 & 138 & 2 \\
\hline & & Ae. vittatus & 1438 & 193 & 270 & 84 & 21 & 0 \\
\hline & & Total & 3806 & 645 & 1012 & 2084 & 1612 & 27 \\
\hline \multirow{10}{*}{\multicolumn{2}{|c|}{ Landing Rates }} & Ae. aegypti formosus & 0.63 & 0.26 & 0.09 & 0.06 & 0.08 & 0.00 \\
\hline & & Ae. africanus & 0.00 & 0.00 & 0.00 & 0.38 & 0.11 & 0.01 \\
\hline & & Ae. dalzieli & 0.09 & 0.02 & 0.12 & 5.33 & 5.27 & 0.06 \\
\hline & & Ae. furcifer & 6.84 & 1.10 & 1.61 & 2.54 & 1.04 & 0.03 \\
\hline & & An. gambiae & 0.04 & 0.30 & 0.37 & 0.05 & 0.11 & 0.00 \\
\hline & & Ae. luteocephalus & 2.90 & 0.42 & 0.86 & 0.85 & 0.23 & 0.01 \\
\hline & & Ae. minutus & 0.56 & 0.03 & 0.36 & 0.00 & 0.00 & 0.00 \\
\hline & & Ae. taylori & 0.22 & 0.03 & 0.12 & 0.12 & 0.08 & 0.00 \\
\hline & & Ma. uniformis & 0.01 & 0.00 & 0.00 & 0.19 & 0.66 & 0.01 \\
\hline & & Ae. vittatus & 6.85 & 0.92 & 1.29 & 0.40 & 0.10 & 0.00 \\
\hline \multirow[t]{15}{*}{ Number of viral strains } & $\mathrm{CHIKV}$ & Ae. aegypti formosus & 1 & 1 & 0 & 0 & 0 & 0 \\
\hline & & Ae. furcifer & 1 & 6 & 11 & 0 & 0 & 0 \\
\hline & & An. gambiae & 0 & 1 & 2 & 0 & 0 & 0 \\
\hline & & Ae. luteocephalus & 2 & 1 & 1 & 0 & 0 & 0 \\
\hline & & Ae. minutus & 1 & 0 & 0 & 0 & 0 & 0 \\
\hline & & Ae. vittatus & 3 & 1 & 0 & 0 & 0 & 0 \\
\hline & YFV & Ae. africanus & 0 & 0 & 0 & 2 & 2 & 0 \\
\hline & & Ae. furcifer & 0 & 0 & 0 & 4 & 4 & 0 \\
\hline & & Ae. luteocephalus & 0 & 0 & 0 & 6 & 1 & 0 \\
\hline & & Ae. taylori & 0 & 0 & 0 & 0 & 1 & 0 \\
\hline & ZIKV & Ae. dalzieli & 0 & 0 & 0 & 0 & 1 & 0 \\
\hline & & Ae. furcifer & 0 & 2 & 5 & 2 & 0 & 0 \\
\hline & & Ae. luteocephalus & 0 & 2 & 7 & 2 & 0 & 0 \\
\hline & & Ae. taylori & 0 & 0 & 0 & 0 & 1 & 0 \\
\hline & & Ma. uniformis & 0 & 0 & 0 & 1 & 0 & 0 \\
\hline \multirow[t]{8}{*}{ MFIR\%o } & $\mathrm{CHIKV}$ & Ae. aegypti formosus & 0.01 & 0.02 & 0.00 & 0.00 & 0.00 & 0.00 \\
\hline & & Ae. furcifer & 0.00 & 0.03 & 0.03 & 0.00 & 0.00 & 0.00 \\
\hline & & An. gambiae & 0.00 & 0.02 & 0.03 & 0.00 & 0.00 & 0.00 \\
\hline & & Ae. luteocephalus & 0.00 & 0.01 & 0.01 & 0.00 & 0.00 & 0.00 \\
\hline & & Ae. minutus & 0.01 & 0.00 & 0.00 & 0.00 & 0.00 & 0.00 \\
\hline & & Ae. vittatus & 0.00 & 0.01 & 0.00 & 0.00 & 0.00 & 0.00 \\
\hline & YFV & Ae. africanus & 0.00 & 0.00 & 0.00 & 0.03 & 0.08 & 0.00 \\
\hline & & Ae. furcifer & 0.00 & 0.00 & 0.00 & 0.01 & 0.02 & 0.00 \\
\hline
\end{tabular}


Table 5 Temporal dynamics of mosquito vectors and arboviruses in southeastern Senegal, 2015 (Continued)

\begin{tabular}{|c|c|c|c|c|c|c|c|c|}
\hline & & Species & July & August & September & October & November & December \\
\hline & & Ae. luteocephalus & 0.00 & 0.00 & 0.00 & 0.03 & 0.02 & 0.00 \\
\hline & & Ae. taylori & 0.00 & 0.00 & 0.00 & 0.00 & 0.06 & 0.00 \\
\hline & ZIKV & Ae. dalzieli & 0.00 & 0.00 & 0.00 & 0.00 & 0.00 & 0.00 \\
\hline & & Ae. furcifer & 0.00 & 0.01 & 0.01 & 0.00 & 0.00 & 0.00 \\
\hline & & Ae. luteocephalus & 0.00 & 0.02 & 0.04 & 0.01 & 0.00 & 0.00 \\
\hline & & Ae. taylori & 0.00 & 0.00 & 0.00 & 0.00 & 0.06 & 0.00 \\
\hline & & Ma. uniformis & 0.00 & 0.00 & 0.00 & 0.03 & 0.00 & 0.00 \\
\hline \multirow[t]{18}{*}{ EIR } & $\mathrm{CHIKV}$ & Ae. aegypti formosus & 0.15 & 0.15 & 0.00 & 0.00 & 0.00 & 0.00 \\
\hline & & Ae. furcifer & 0.15 & 0.89 & 1.57 & 0.00 & 0.00 & 0.00 \\
\hline & & An. gambiae & 0.00 & 0.15 & 0.29 & 0.00 & 0.00 & 0.00 \\
\hline & & Ae. luteocephalus & 0.30 & 0.15 & 0.14 & 0.00 & 0.00 & 0.00 \\
\hline & & Ae. minutus & 0.15 & 0.00 & 0.00 & 0.00 & 0.00 & 0.00 \\
\hline & & Ae. vittatus & 0.44 & 0.15 & 0.00 & 0.00 & 0.00 & 0.00 \\
\hline & & All vectors & 1.18 & 1.48 & 2.00 & 0.00 & 0.00 & 0.00 \\
\hline & YFV & Ae. africanus & 0.00 & 0.00 & 0.00 & 0.30 & 0.29 & 0.00 \\
\hline & & Ae. furcifer & 0.00 & 0.00 & 0.00 & 0.59 & 0.57 & 0.00 \\
\hline & & Ae. luteocephalus & 0.00 & 0.00 & 0.00 & 0.89 & 0.14 & 0.00 \\
\hline & & Ae. taylori & 0.00 & 0.00 & 0.00 & 0.00 & 0.14 & 0.00 \\
\hline & & All vectors & 0.00 & 0.00 & 0.00 & 1.48 & 0.86 & 0.00 \\
\hline & ZIKV & Ae. dalzieli & 0.00 & 0.00 & 0.00 & 0.00 & 0.14 & 0.00 \\
\hline & & Ae. furcifer & 0.00 & 0.30 & 0.71 & 0.30 & 0.00 & 0.00 \\
\hline & & Ae. luteocephalus & 0.00 & 0.30 & 1.00 & 0.30 & 0.00 & 0.00 \\
\hline & & Ae. taylori & 0.00 & 0.00 & 0.00 & 0.00 & 0.14 & 0.00 \\
\hline & & Ma. uniformis & 0.00 & 0.00 & 0.00 & 0.15 & 0.00 & 0.00 \\
\hline & & All vectors & 0.00 & 0.59 & 1.71 & 0.74 & 0.29 & 0.00 \\
\hline
\end{tabular}

MFIR\%o Minimum field infection rate per thousand mosquitoes tested, EIR Entomological inoculation rates (number of infected mosquito bites per person per month), CHIKV chikungunya virus, YFV yellow fever virus, ZIKV Zika virus; Ae., Aedes; An., Anopheles; Ma., Mansonia

(forest, barren, savannah, agriculture, and urban), which were previously classified by remote sensing and geospatial analyses [1, 7, 32-34]. Mosquitoes were collected by human landing collection for one evening (from 6 to 9 $\mathrm{PM})$ per month in each site. Three collectors were used per site in savannah (S), agriculture (A), barren land (B), forest at the ground level (FG), forest in the canopy $(\mathrm{FC})$, villages indoors (VI) and villages outdoors (VO). To better understand the dynamics of vectors and viruses in the domestic environment, mosquito collections in villages were continued until $6 \mathrm{AM}$. Collection within villages were separated hourly into separate containers.

Mosquitoes were morphologically identified to the species level following appropriate keys [35-40]. Following morphological identification on a chill table, mosquitoes were pooled (maximum of 35 and average 3.9 mosquitoes per pool) by species (one species per pool), sex, and site (one site per pool), and stored in liquid nitrogen in the field and at $-80^{\circ} \mathrm{C}$ in the lab for virus testing. No specific permit was needed for sample collection.

\section{Detection of virus in mosquito pools}

After homogenization in $2.5 \mathrm{ml}$ of Leibovit's L-15 cell culture medium (Gibco BRL, GrandIsland, NY) containing $20 \%$ fetal bovine serum (FBS), mosquito pools were centrifuged for $20 \mathrm{~min}$ at $10,000 \mathrm{x} \mathrm{g}$ at $4{ }^{\circ} \mathrm{C}$ for clarification. Viral suspensions were then filtered using a $1 \mathrm{ml}$ syringe (Artsana, Como, Italy), sterilized with $0.20 \mu \mathrm{m}$ filters (Sartorius, Göttingen, Germany). Viruses isolation attempts were made by inoculating $200 \mu \mathrm{l}$ of the supernatant of the mosquito homogenate into C6/36 cells (Ae. albopictus) as described previously [41]. Viruses were identified, after 78 days of incubation, by indirect immunofluorescence with 7 in-house hyper-immune mouse ascites fluids specific to individual or groups of African Flaviviruses, Bunyaviruses, Orbiviruses and Alphaviruses. The identification of viruses were confirmed by complement fixation and seroneutralization tests $[4,6,7]$. All viral tests were carried out by the WHO Collaborating Center of Reference and Research on Arboviruses and hemorrhagic fever viruses of the Institut Pasteur de Dakar. 


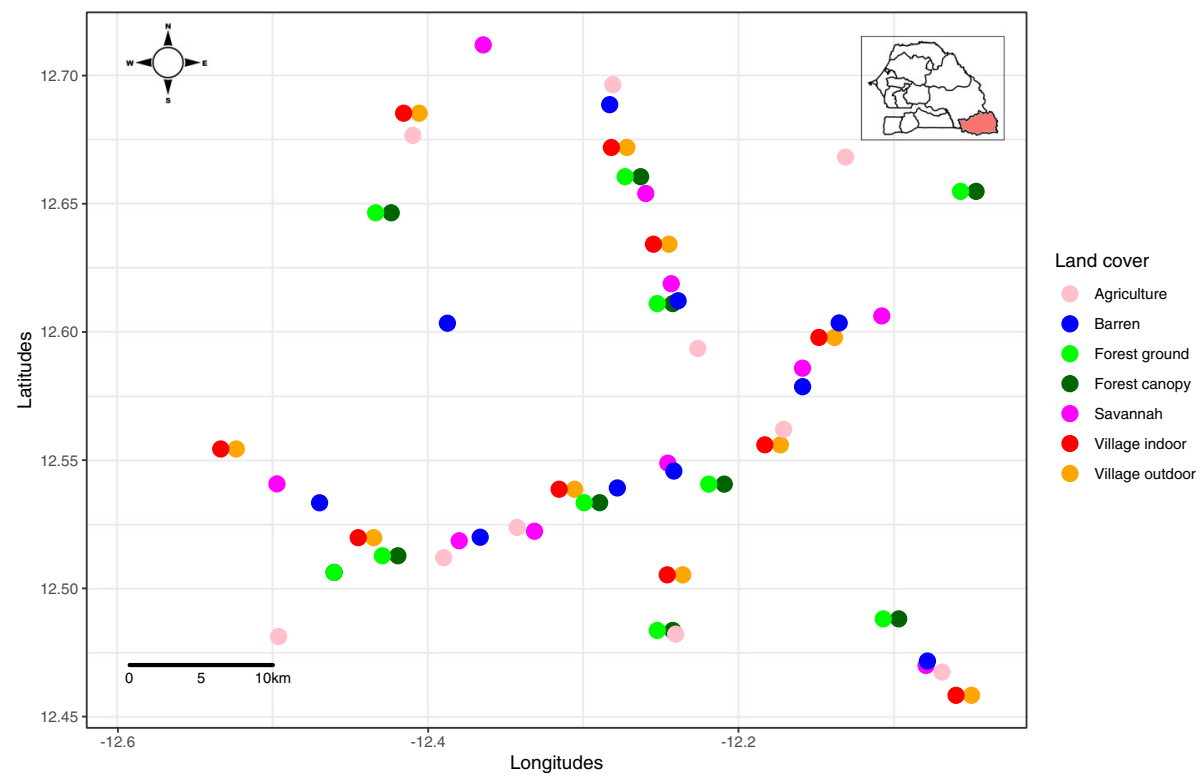

Fig. 2 Study sites in southeastern Senegal

For the RT-PCR assay, the RNA was extracted from $100 \mu \mathrm{l}$ of mosquito supernatants using the QiaAmp Viral RNA Extraction Kit (Qiagen, Heiden, Germany) according to the manufacturer's instructions. RNA was amplified using real-time RT-PCR assay and an ABI Prism 7000 SDS Real-Time apparatus (Applied Biosystems, Foster City, CA) using the Quantitect kit (Qiagen, Hilden, Germany). The real-time RT-PCR protocol (including program, volumes, thermal profiles, primers and sequences probes) were previously described in detail (See Diallo et al. [7] for CHIKV, Diallo et al. [4] for YFV, and Faye et al. [42] for ZIKV).

\section{Data analysis}

For analysis of the distribution of vector species among land cover classes, the mean number of mosquito females collected per site per evening was used as a measure of absolute abundance. The minimum field infection rate (MFIR\%) was calculated as the number of positive per 1000 mosquitoes tested. The entomologic inoculation rate (EIR) defined as the number of infected mosquito bites per human per month, or transmission season (September to December) was also calculated. Differences of frequencies between groups were tested by the $x^{2}$ or Fisher exact test. All analyses were carried out using $R$ [43].

\section{Abbreviations}

ZIKV: Zika virus; YFV: Yellow fever virus; CHIKV: Chikungunya virus; C6/

36: Aedes albopictus; S: Savannahs; A: Agricultures; B: Barren lands; FG: Forests at the ground level; FC: Forests in the canopy; VI: Villages indoor; VO: Villages outdoor; MFIR\%: Minimum field Infection Rate; EIR: Entomological Inoculation rate; K-W: Kruskal-Wallis; Ae:: Aedes; Cx:: Culex; An.: Anopheles; Ma.: Mansonia; Er:: Eretmapodites; Ur.: Uranotaenia

\section{Acknowledgements}

The authors would like to thank Mamoudou Ba and Arame BA for their technical assistance and all the population of Barkedji for their collaboration. We thank Kathryn Hanley for editing English usage and grammar.

\section{Authors' contributions}

$\mathrm{DD}, \mathrm{MD}, \mathrm{YB}, \mathrm{ID}, \mathrm{GF}$ and OF conceived and designed the study. DD,CTD, and $A G$ carried out the field work. GF and OF performed virus tests. DD, MD, YB, ID, GF and OF analyzed the data and drafted the manuscript. All authors read, critically revised and approved the final manuscript.

\section{Funding}

Not applicable.

Availability of data and materials

All data generated or analysed during this study are included in this published article. Additional data may be available from the corresponding author upon reasonable request.

\section{Ethics approval and consent to participate}

The study followed the protocol SEN29/08 approved by le 'Comité National d'Éthique du Ministère de la Santé et de la Prévention' of Senegal (2472 MS/ DS/DER, 0081 MS/DS/CNRS). No specific permit was needed for sample collection. The study protocol was carefully explained to the chief and inhabitants of each village investigated to obtain their informed oral consent. Informed oral consent was also obtained from the heads of each household and agricultural land cover in which collection were undertaken.

\section{Consent for publication}

Not applicable.

\section{Competing interests}

The authors declare that they have no competing interests.

\section{Author details}

'Pôle de Zoologie Médicale, Institut Pasteur de Dakar, 36 Avenue Pasteur, BP 220, Dakar, Senegal. ${ }^{2}$ Pôle de Virologie, Institut Pasteur de Dakar, 36 Avenue Pasteur, BP 220, Dakar, Senegal. 
Received: 4 March 2020 Accepted: 18 June 2020

Published online: 26 June 2020

\section{References}

1. Diallo D, Diagne CT, Buenemann M, Ba Y, Dia I, Faye O, et al. Biodiversity pattern of mosquitoes in southeastern Senegal, epidemiological implication in Arbovirus and malaria transmission. J Med Entomol. 2019:56:453-63.

2. Cornet M, Robin Y, Chateau R, Hème G, Adam C, Valade M, et al. Isolements d'arbovirus au Sénégal oriental apartir de moustiques (1972-1977) et notes Sur l'épidémiologie des virus transmis par les Aedes, en particulier du virus amaril. Cah ORSTOM Sér Ent Méd Parasitol. 1979;17:149-63.

3. Diallo M, Ba Y, Sall AA, Diop OM, Ndione JA, Mondo M, et al. Amplification of the sylvatic cycle of dengue virus type 2, Senegal, 1999-2000: entomologic findings and epidemiologic considerations. Emerg Infect Dis. 2003:9:362-7.

4. Diallo D, Sall AA, Diagne CT, Faye O, Hanley KA, Buenemann M, et al. Patterns of a sylvatic yellow fever virus amplification in southeastern Senegal, 2010. Am J Trop Med Hyg. 2014;90:1003-13.

5. Diallo D, Chen R, Diagne CT, Ba Y, Dia I, Sall AA, et al. Bloodfeeding patterns of sylvatic arbovirus vectors in southeastern Senegal. Trans R Soc Trop Med Hyg. 2013;107:200-3

6. Diallo D, Sall AA, Diagne CT, Faye O, Faye O, Ba Y, et al. Zika virus emergence in mosquitoes in southeastern Senegal, 2011. PLoS One. 2014;9: e109442.

7. Diallo D, Sall AA, Buenemann M, Chen R, Faye O, Diagne CT, et al. Landscape ecology of sylvatic chikungunya virus and mosquito vectors in southeastern Senegal. PLoS Negl Trop Dis. 2012;6:e1649.

8. Brown C. Zika virus outbreaks in Asia and South America. Can Med Assoc J. 2016;188:E34.

9. Lindholm DA, Myers T, Widjaja S, Grant EM, Telu K, Lalani T, et al. Mosquito exposure and Chikungunya and dengue infection among travelers during the Chikungunya outbreak in the Americas. Am J Trop Med Hyg. 2017;96: 903-12

10. Franco L, Di Caro A, Carletti F, Vapalahti O, Renaudat C, Zeller H, et al. Recent expansion of dengue virus serotype 3 in West Africa. Euro Surveill. 2010;15:19490

11. Bocanegra C, Anton A, Sulleiro E, Pou D, Salvador F, Roure S, et al. Imported cases of Chikungunya in Barcelona in relation to the current American outbreak. J Travel Med. 2016:23:tav003.

12. Diallo M, Thonnon J, Traore-Lamizana M, Fontenille D. Vectors of Chikungunya virus in Senegal: current data and transmission cycles. Am J Trop Med Hyg. 1999;60:281-6.

13. Faye $\mathrm{O}, \mathrm{Ba} Y$, Faye $\mathrm{O}$, Talla $\mathrm{C}$, Diallo $\mathrm{D}$, Chen $\mathrm{R}$, et al. Urban epidemic of dengue virus serotype 3 infection, Senegal, 2009. Emerg Infect Dis. 2014;20: 456-9.

14. Leroy EM, Nkoghe D, Ollomo B, Nze-Nkogue C, Becquart P, Grard G, et al. Concurrent chikungunya and dengue virus infections during simultaneous outbreaks, Gabon, 2007. Emerg Infect Dis. 2009;15:591-3.

15. Althouse BM, Hanley KA, Diallo M, Sall AA, Ba Y, Faye O, et al. Impact of climate and mosquito vector abundance on sylvatic arbovirus circulation dynamics in Senegal. Am J Trop Med Hyg. 2015;92:88-97.

16. Adam F, Diquette JP. Virus d'Afrique [base de données]. Dakar: Institut Pasteur de Dakar. Centre collaborateur OMS de référence et de recherche pour les arbovirus et les virus de fièvres hémorrhagiques (CRORA). 2012

17. Diallo D, Dia I, Diagne CT, Gaye A, Diallo M. Emergences of chikungunya and Zika in Africa: Chikungunya and Zika Viruses. Elsevier: Amsterdam, The Netherlands; 2018. p. 87-133.

18. Traore-Lamizana M, Zeller H, Monlun E, Mondo M, Hervy JP, Adam F, et al. Dengue 2 outbreak in southeastern Senegal during 1990: virus isolations from mosquitoes (Diptera: Culicidae). J Med Entomol. 1994;31:623-7.

19. Brasil $P$, Calvet GA, Siqueira AM, Wakimoto $M$, de Sequeira $P C$, Nobre $A$, et al. Zika virus outbreak in Rio de Janeiro, Brazil: clinical characterization, Epidemiological and Virological Aspects. PLoS Negl Trop Dis. 2016;10: e0004636.

20. Rodriguez-Morales AJ. Zika: the new arbovirus threat for Latin America. J Infect Dev Ctries. 2015;9:684-5

21. Lourenço J, de Lourdes MM, Valdez T, Monteiro Rodrigues J, Pybus O, Rodrigues FN. Epidemiology of the Zika virus outbreak in the Cabo Verde Islands, West Africa. PLoS Curr. 2018;10: 19433b1e4d007451c691f138e1e67e8c.
22. Rückert C, Weger-Lucarelli J, Garcia-Luna SM, Young MC, Byas AD, Murrieta RA, et al. Impact of simultaneous exposure to arboviruses on infection and transmission by Aedes aegypti mosquitoes. Nat Commun. 2017;8:15412.

23. Goertz GP, Vogels CBF, Geertsema C, Koenraadt CJM, Pijlman GP. Mosquito co-infection with Zika and chikungunya virus allows simultaneous transmission without affecting vector competence of Aedes aegypti. PLoS Negl Trop Dis. 2017;11:e0005654

24. Nuckols JT, Huang Y-JS, Higgs S, Miller AL, Pyles RB, Spratt HM, et al. Evaluation of simultaneous transmission of Chikungunya virus and dengue virus type 2 in infected Aedes aegypti and Aedes albopictus (Diptera: Culicidae). J Med Entomol. 2015:52:447-51.

25. Vazeille M, Mousson L, Martin E, Failloux A-B. Orally co-infected Aedes albopictus from La Reunion Island, Indian Ocean, can deliver both dengue and chikungunya infectious viral particles in their saliva. PLoS Negl Trop Dis. 2010:4:e706.

26. Mcintosh BM, Paterson HE, Mcgillivray G, Desousa J. Further studies on the chikungunya outbreak in southern rhodesia in 1962. i. Mosquitoes, wild primates and birds in relation to the epidemic. Ann Trop Med Parasitol. 1964;58:45-51.

27. Cornet M, Robin Y, Hannoun C, Corniou B, Bres P, Causse G. An epidemic of yellow fever in Senegal in 1965. Epidemiological studies. Bull World Health Organ. 1968:39:845-58.

28. Moore DL, Reddy S, Akinkugbe FM, Lee VH, David-West TS, Causey OR, et al. An epidemic of chikungunya fever at Ibadan, Nigeria, 1969. Ann Trop Med Parasitol. 1974;68:59-68.

29. Robert V, Lhuillier M, Meunier D, Sarthou UL, Monteny N, Digoutte JP, et al. Yellow fever virus, dengue 2 and other arboviruses isolated from mosquitos, in Burkina Faso, from 1983 to 1986. Entomological and epidemiological considerations. Bull Soc Pathol Exot. 1993;86:90-100.

30. Diallo D, Diagne CT, Hanley KA, Sall AA, Buenemann M, Ba Y, et al. Larval ecology of mosquitoes in sylvatic arbovirus foci in southeastern Senegal. Parasit Vectors. 2012;5:286

31. Haddow AJ, Ssenkubuge Y. The mosquito of bwamba county, Uganda. IX Further studies on the biting behaviour of an outdoor population of the Anopheles gambiae Giles complex. Bull Entomol Res. 1973;62:407-14.

32. Richman R, Diallo D, Diallo M, Sall AA, Faye O, Diagne CT, et al. Ecological niche modeling of Aedes mosquito vectors of chikungunya virus in southeastern Senegal. Parasit Vectors. 2018;11:255.

33. Young Kl, Medwid JT, Azar SR, Huff RM, Drumm H, Coffey LL, et al. Identification of mosquito Bloodmeals collected in diverse habitats in Malaysian Borneo using COI barcoding. Trop Med Infect Dis. 2020;5:51.

34. Hendy A, Hernandez-Acosta E, Chaves BA, Fé NF, Valério D, Mendonça C, et al. Into the woods: changes in mosquito community composition and presence of key vectors at increasing distances from the urban edge in urban forest parks in Manaus, Brazil. Acta Trop. 2020;206:105441.

35. Huang Y-M. Aedes (Stegomyia) bromeliae (Diptera: Culicidae), the yellow fever virus vector in East Africa. J Med Entomol. 1986;23:196-200.

36. Huang Y-M, Ward RA. A pictorial key for the identification of the mosquitoes associated with yellow fever in Africa. Mosq Syst. 1981;13:138-49.

37. Edwards FW. Mosquitoes of the Ethiopian region: III Culicine adults and pupae. London: British Museum (Natural History); 1941.

38. Ferrara L, Germain M, Hervy JP. Aedes (Diceromyia) furcifer (Edwards, 1913) et Aedes (Diceromyia) taylori Edwards, 1936: le point Sur la différenciation des adultes. Cah ORSTOM Sér Ent Méd Parasitol. 1984;22:179-83.

39. Jupp PG. Mosquitoes of southern Africa: Culicinae and Toxorhynchitinae Hartebeespoort: Ekogilde cc Publishers; 1997.

40. Diagne N, Fontenille D, Konate L, Faye O, Lamizana MT, Legros F, et al. Anopheles of Senegal. An annotated and illustrated list. Bull Soc Pathol Exot. 1994:87:267-77.

41. Digoutte JP, Calvo-Wilson MA, Mondo M, Traore-Lamizana M, Adam F. Continuous cell lines and immune ascitic fluid pools in arbovirus detection. Res Virol. 1992;143:417-22

42. Faye O, Faye O, Diallo D, Diallo M, Weidmann M, Sall AA. Quantitative realtime PCR detection of Zika virus and evaluation with field-caught mosquitoes. Virology J. 2013;10:311.

43. R core Team. R: A language and environment for statistical computing. 2016

\section{Publisher's Note}

Springer Nature remains neutral with regard to jurisdictional claims in published maps and institutional affiliations. 